International Review of Research in Open and Distributed Learning Volume 16, Number 2

April - 2015

\title{
A Snapshot of Online Learners: e-Readiness, e- Satisfaction and Expectations
}

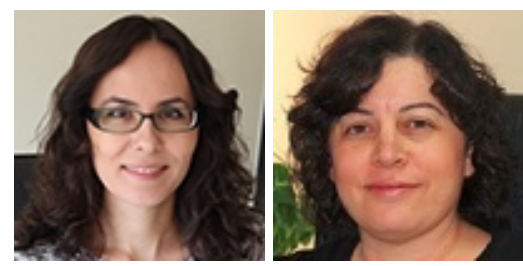

Hale Ilgaz and Yasemin Gülbahar

Ankara University, Turkey

\begin{abstract}
The popularity of online programs that educational institutions offer is continuously increasing at varying degrees, with the major demand coming from adult learners who have no opportunity to access traditional education. These adult learners have to be sufficiently ready and competent for online learning, and have their own varied expectations from the online learning process. Hence, this mixed method study is conducted to explore the participants' readiness and expectations at the beginning and their satisfaction levels at the end of an online learning experience. An ereadiness scale and an e-satisfaction scale was administered as quantitative measures, with openended questions gathering qualitative data. Participants of the research were registered to different e-learning programs at Ankara University Distance Education Center, Turkey, during the 2013-2014 academic year. Analysis of both quantitative and qualitative data revealed facts about online learners, which should prove useful to both e-instructors and e-program administrators.
\end{abstract}

Keywords: Online learning; blended learning; satisfaction; expectations 


\section{Introduction}

The number of online programs that educational institutions offer is continuously increasing at varying degrees, namely associate, undergraduate and even graduate degrees. Most of these programs address adult learners who have a need for higher education degrees, but lack the opportunity to access traditional education. Whether they simply prefer or are obligated to enroll in online education, these adult learners have to be ready and have to possess some basic technical skills in order to benefit from online learning. They also have different expectations from the online learning environment. Hence, assessing to what extent they are ready for elearning and revealing their expectations of e-learning is important to the design and delivery processes of e-learning. Moreover, learners' satisfaction levels are important for educators, instructional designers and other stakeholders, in order to modify and revise both the academic and administrative aspects of an e-learning program so as to increase the quality of the learning environment. Hence, in researching the success of e-Learning, it is important to reveal not only the readiness and expectations of learners, but also the level of satisfaction about various dimensions of the learning process (Gulbahar \& Cinar, 2011; Gülbahar, 2012).

Being ready and having expectations as an input to the e-Learning process, and satisfaction levels as an output to see what came out of the process, can be perceived as two important variables to be considered in any future interventions in an e-Learning environment. By observing changes in these variables, it may be possible to improve quality by way of a scientific, reliable and valid method. Owing to these facts, this research study is conducted to observe online learners before and after online learning through quantitative measures. In other words, these variables can be used to assess the quality of e-learning, and also to record their perceptions about the experience throughout the whole process.

\section{e-Learning and Readiness}

e-Learning can be defined as the transformation of teaching-learning processes through learnercentered approaches with the support of information and communication technologies (ICT) (Aoki, 2010). In parallel with this definition, e-readiness is defined as the measure of the degree to which a community may be eager and prepared to make benefit of using ICT (Dada, 2006). Although there are so many studies regarding factors affecting outputs of e-Learning, few studies exist in the literature about the effects of e-readiness and possible factors that affect the outputs of e-Learning (Keramati, Afshari-Mofrad \& Kamrani, 2011). Keramati, Afshari-Mofrad and Kamrani (2011) analyzed the role of e-readiness factors in e-learning outcomes. They identified three groups and came up with a structural equation model; these factors were technical, organizational and social. Results of the study showed that organizational readiness factor has the most important effect on outcomes.

Moreover, studies about e-readiness in higher education are also limited (Darab \& Montazer, 2011). It is observed that ICT competencies and access to technology and resources are among the

This work is licensed under a Creative Commons Attribution 4.0 International License. 
factors that should be considered for e-readiness (Stephen, Mutula \& Brakel, 2006; Dada, 2006; Hanafizadeh, Hanafizadeh \& Khodabakhshi, 2009).

In their study, Shraim and Khlaif (2010) indicated four dimensions for e-readiness as usability, individual competency, motivation and obstacles. In another study, Watkins, Leigh and Triner (2004) investigated e-readiness by considering access to technology, technical competencies, motivation, online audio-video, and discussions as factors. More recently, a study conducted by Yurdugül and Sirakaya (2013) aimed to develop an online learning readiness scale, by translating the original scale developed by Hung, Chou, Chen \& Own (2010) into Turkish. The scale is composed of five dimensions, which are, self-directed learning, motivation for learning, computer/ internet self-efficacy, learner control, and online communication self-efficacy.

Thus, individual properties, ICT competencies and motivation, together with access to technology, are identified as key factors for e-readiness across almost all research studies. Moreover, there may be some other factors that affect students' success and are therefore also important for e-readiness. Based on the existing literature, factors that should be considered for e-readiness are shown in Figure 1.

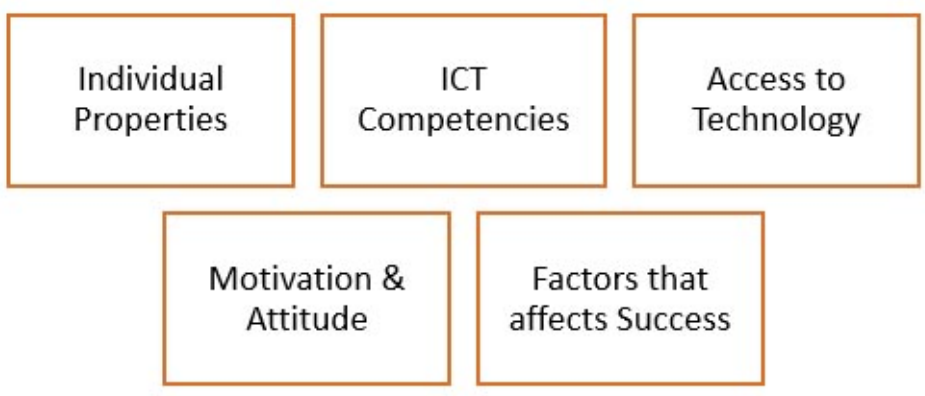

Figure 1. e-Readiness scale dimensions.

\section{e-Learning and Satisfaction}

Satisfaction of online learners is one of the important factors that shapes the design, delivery and implementation of e-Learning and almost certainly affects the quality. As an output variable, satisfaction even may reveal what happened during the whole process and may be considered as the determinant of how successful was the course, program, instructor, selected technologies and design, based on the scope of the questions asked. Beqiri, Chase and Bishka (2009) conducted a study to unveil the factors affecting satisfaction. They found out that those learners who have positive attitudes towards online technologies and have acquired sufficient ICT competencies are more satisfied when compared to others. Similarly, Pena and Yeung (2010) investigated a similar

This work is licensed under a Creative Commons Attribution 4.0 International License. 
phenomenon and concluded that satisfaction decreases in parallel with a decrease in ICT competencies.

J ung-Wan and Mendlinger (2011) investigated the effect of perceived self-efficacy on perceptions of ease of use and usefulness of online learning systems, together with its effects on behavioral intention toward online learning acceptance and student satisfaction. The researchers concluded that perceived self-efficacy is important for online learning acceptance and perceived usefulness of online learning systems positively influences student satisfaction.

Palmer and Holt (2009) used a survey to find out what contributes to learner satisfaction. Their survey was composed under the headings of organization and structure, teaching and learning, teaching staff and other students, assessment, attribute development, and unit performance. The researchers concluded that a very high proportion of learner satisfaction comes from how confident learners felt about their ability to communicate and learn online, having a clear understanding of what was required for them to succeed, and how well they thought they were performing.

According to another study conducted by Machado (2007), it was seen that an increase in the opportunities provided, and the competencies of administrative and academic staff leads to an increase in the satisfaction of learners. Moreover, technological competencies of learners also affect the satisfaction levels of learners (Machado, 2007). Lee and Rha (2009) investigated the influence of structure in terms of instructional design, and interaction in terms of management style, on student achievement and satisfaction in a web-based distance learning environment. The researchers concluded that learners who participated in a structured course were more satisfied with structure, whereas learners who participated in the interactive course were more satisfied with interpersonal interaction. On the other hand, Palmer and Holt (2010) stated that learners value the features of a Learning Management System (LMS) and that their satisfaction can increase based on the features that the LMS provides to them.

Hence, from these and many other research studies, it can be concluded that the technical competencies of learners, teaching process, instructional content, technical and pedagogical competencies of e-Tutors, instructional technologies attitudes towards e-Learning approach, usability of LMS and interaction levels can all play an important role in learner satisfaction. Hence, the dimensions in Figure 2 were considered for the current research study in order to reveal the satisfaction levels of learners. 

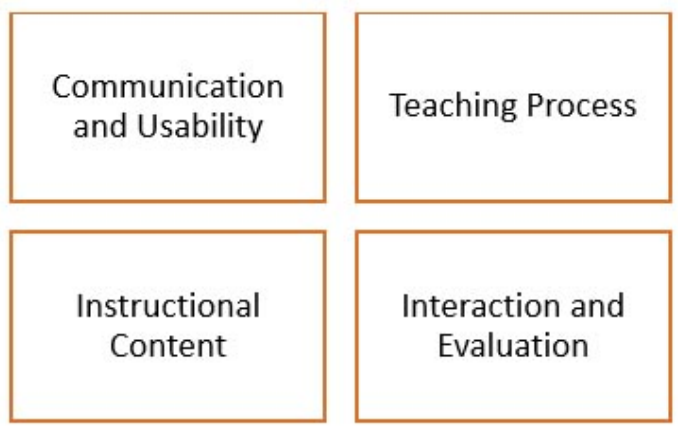

Figure 2. e-Satisfaction scale dimensions.

\section{Distance Education Programs Offered by Ankara University}

The Distance Education Center of Ankara University, Turkey, at which this study has been conducted, delivers various diploma programs for college, undergraduate and graduate degrees. The two-year college programs include computer programming, medical documentation, insurance and banking, tourism and catering services, and a judicial services support program. In addition to two-year college programs, another popular program is the Divinity Diploma Upgrade, for divinity students who already hold two-year college diplomas. Ankara University also has graduate level (MS degree) programs, while non-dissertation programs have been developed to increase professional competencies of students and professionals in the subject areas of Human Relations, Journalism, Health Management and Social Services. In addition, some traditional courses are also given through either blended learning or e-learning. In total, the online learning programs and courses have 16,000 learners, of which 14,000 are in college programs, 1,776 in undergraduate programs and 231 in graduate programs.

Ankara University Distance Education Center uses various technologies to create and deliver eLearning programs. Moodle is used as the learning management system, whereas various commercial and open-source virtual class software is also used. For content creation, a national product named "Etudio", together with some other commercial and open-source software is used by the instructional designers. Video recordings are also produced by media experts as instructional content for e-Learning courses. 


\section{Method}

\section{Research Design}

This research is designed as a mixed-method study where qualitative and quantitative methods were employed. An e-readiness scale and an e-satisfaction scale was administered to the participants, acting as quantitative measures, with each scale having an open-ended question posed to learners in terms of gathering qualitative data on the perceptions of participants. In the quantitative research, descriptive statistics have been used, and content analysis conducted to analyze the open-ended questions, with researchers generating codes and themes based on interpretations performed.

\section{Research Questions}

- To what extent are the participants ready for e-Learning?

- What factors affect participants' perceptions about their e-Readiness?

- To what extent are participants satisfied with their e-Learning experience?

- What factors affect participants' perceptions of their e-satisfaction about e-Learning experience?

\section{Participants}

Participants were enrolled in various e-learning programs. These programs were five foundation degrees, one bachelor degree and four post graduate degree programs. The number of respondents to the e-Readiness scale were 2,334, whereas for the e-satisfaction scale it was 2,288. Demographics for the participants of the e-Readiness scale are presented in Table 1.

Table 1

Participant Demographics

\begin{tabular}{|l|l|r|r|}
\hline \multicolumn{2}{|c|}{} & Frequency & \multicolumn{1}{c|}{ Percent } \\
\hline \multirow{3}{*}{ Gender } & Female & 1,341 & 57.5 \\
\cline { 2 - 4 } & Male & 993 & 42.5 \\
\hline \multirow{2}{*}{ Marital Status } & Single & 1,085 & 46.5 \\
\cline { 2 - 4 } & Married & 1,249 & 53.5 \\
\hline \multirow{2}{*}{ Total } & 2,334 & 100.0 \\
\hline
\end{tabular}

This work is licensed under a Creative Commons Attribution 4.0 International License. 


\section{Data Collection Instruments}

The e-Readiness scale was used to identify the participants' level of readiness for e-learning at the beginning of the semester. This scale has been designed as a 5-point Likert-type scale and involves 26 items, plus one open-ended question. The scale has five factors which are individual properties, ICT competencies, access to technology, motivation and attitude and factors that affect success. The scale was previously proven to be reliable and valid with a Cronbach $\alpha$ value of 0.93 (Gülbahar, 2012). For gathering the expectations of the learners, one open-ended question was also asked to participants, namely “What is your reason for choosing e-learning?"

The e-Satisfaction scale was used to identify participants' level of satisfaction in the e-learning environment at the end of the semester. This scale has been designed as a 5-point Likert-type scale and involves 29 items, plus one open-ended question. The scale has four factors which are communication and usability, teaching process, instructional content, and interaction and evaluation. The scale was previously proven to be reliable and valid with a Cronbach $\alpha$ value of 0.97 (Gülbahar, 2012). An open-ended question was used to reveal opinions of the participants, namely “What is your opinion about the e-learning program?"

\section{Data Analysis}

SPSS 17.0 statistical analysis program was used for quantitative data analysis and MS Excel was used in the qualitative analysis. A total of 1,256 participants answered the open-ended question in the e-Readiness scale and 252 participants in the e-satisfaction scale. From gathering these responses, a process of coding was conducted.

For the qualitative analysis, inductive coding technique was used. This coding separates according to three groups (Strauss \& Corbin, 1990):

- In open coding, the researcher deals with the labeling and categorizing of phenomena as indicated by the data.

- Axial coding refers to the process of developing main categories and their sub-categories.

- Selective coding involves the integration of the categories that have been developed to form the initial theoretical framework.

In this research coding was conducted according to the initial theoretical framework and researchers analyzed data via substantial themes.

Triangulation validation strategy was used in this research for validity (Miles \& Huberman, 1994), whilst intercoder agreement strategy was used for reliability. Two different coders analyzed the codes and themes. For this data, Cohen's Kappa coefficient was calculated and found to be 0.76, which is within the range of acceptance (Krippendorff, 2004; Landis \& Koch, 1977).

This work is licensed under a Creative Commons Attribution 4.0 International License. 


\section{Results}

\section{Findings about Participants' e-Readiness}

The quantitative data gathered via the e-Readiness scale was analyzed, and based on the results, it is clear that the dimension of access to technology has a bigger effect on participants' readiness. Success factors, ICT competencies, motivation and attitude, and personal characteristics follow the access to technology dimension. The result of the descriptive analysis of the data from the eReadiness scale for each dimension is presented in Table 2.

Table 2

E-Readiness Scale Results

\begin{tabular}{|l|c|c|c|c|c|}
\hline & $\mathrm{N}$ & Min & Max & Mean & $\begin{array}{c}\text { Std } \\
\text { Dev }\end{array}$ \\
\hline Individual Properties & 2334 & 4 & 20 & 3.05 & 3.87 \\
\hline ICT Competencies & 2334 & 4 & 20 & 3.79 & 4.39 \\
\hline Access to Technology & 2334 & 8 & 40 & 3.92 & 8.47 \\
\hline Motivation \&Attitude & 2334 & 4 & 20 & 3.53 & 3.91 \\
\hline $\begin{array}{l}\text { Factors that affects } \\
\text { Success }\end{array}$ & 2334 & 6 & 30 & 3.94 & 5.90 \\
\hline Total & 2334 & 26 & 130 & 3.71 & 22.02 \\
\hline
\end{tabular}

As seen, the most important dimension related to participants' readiness is access to technology. The results of the questionnaire represent the ability of participants to access courses from their homes or any other place they wanted, making use of computers which have good hardware and software. They also think that interacting with the instructor, the frequency of involvement to the online interactions and being provided with technical and administrative support, are contributing factors in making them successful.

\section{Factors Affecting Participants' Perceptions about e-Readiness}

In terms of qualitative measures, answers supplied by 1,256 participants to the open-ended question on e-Readiness were analyzed, and 26 codes and nine themes were noted. The emerging themes are presented in Table 3. These themes are also factors that affect participant's perceptions of e-Readiness. 
Table 3

Emerging Themes for e-Readiness

\begin{tabular}{|l|c|c|}
\hline Themes & Freq. & Pct (\%) \\
\hline Individual factors (responsibilities) & 830 & 66.0 \\
\hline Accessibility & 206 & 16.0 \\
\hline Getting degree & 78 & 6.0 \\
\hline Delivery approach & 60 & 5.0 \\
\hline Time management & 55 & 8.0 \\
\hline Variety of instructional materials & 36 & 3.0 \\
\hline Effective learning & 29 & 2.3 \\
\hline Interaction \& Communication & 18 & 2.0 \\
\hline Institutional factor (trust/prestige) & 11 & 0.9 \\
\hline
\end{tabular}

When values of the themes are analyzed, it is noted that accessibility and individual responsibilities have more effect as to why they chose e-learning. According to this finding, the following opinions were offered by participants.

"I can access the system without time and location problems that I have because of my intense work schedule time, which are a limitation for me. I am feeling more independent and this system is more technological".

"I chose e-learning because I am married and have a small child".

'I am living abroad and I haven't had the chance to attend formal training, hence I chose e-learning”.

Moreover participants stated that economic issues, obligations, anxiety disorders, health problems, attendance flexibility, strength of interaction and communication, variety of materials and institution prestige as other influential factors in choosing e-learning. One participant who has an anxiety disorder expressed these thoughts:

"I feel anxious while I am working face-to-face in a classroom and this makes me unsuccessful. When I manage my own learning process I am more successful, and in this way I can manage my own responsibility and this makes me more motivated". 
The participants stated that they overcame problems arising from familial, economic or health issues which prevented them participating in formal training, through the flexible structure provided by distance education. This supports the time-space freedom which is the most important advantage of distance education. Individuals who consider distance education as an alternative, indicated that their expectations were affected due to the accessibility and difference in methods employed in distance education. Having a degree also showed up as another important expectation for the individuals. However, it also provides an important advantage in terms of time management for individuals who want education for personal development and lifelong learning, but need to manage this alongside their business life. Other aspects that affected the participants' expectations are: distance education offering alternative types of content that provide effective learning, and the prestige of the institution where the individuals hope to be educated.

\section{Findings about Participants' e-Satisfaction}

Data gathered by way of the e-Satisfaction scale was analyzed as a quantitative measure. The result of the descriptive analysis of data from the e-Satisfaction scale is presented in Table 4.

Table 4

\section{E-Satisfaction Scale Results}

\begin{tabular}{|l|r|r|r|r|r|}
\hline & $\mathrm{N}$ & Min & Max & Mean & Std Dev \\
\hline $\begin{array}{l}\text { Communication and } \\
\text { Usability }\end{array}$ & 2288 & 7 & 35 & 3.26 & 7.48 \\
\hline Teaching Process & 2288 & 8 & 40 & 3.19 & 8.71 \\
\hline Instructional Content & 2288 & 4 & 20 & 3.28 & 4.64 \\
\hline $\begin{array}{l}\text { Interaction and } \\
\text { Evaluation }\end{array}$ & 2288 & 10 & 50 & 3.07 & 11.14 \\
\hline Total & 2288 & 29 & 145 & 3.18 & 30.03 \\
\hline
\end{tabular}

When Table 4 is analyzed, it is seen that the participants' satisfaction levels are mainly affected by instructional content, communication and usability, and teaching process. It is seen that, usage of the different kinds of interaction tools, activities planned in order to increase the interaction and usage of the different kinds of evaluation methods are the most important factors which affect the participants' satisfaction. Steering related learning process, asynchronous interaction opportunities for those not able to attend synchronous activities, and experienced instructors are also seen as important within the process.

This work is licensed under a Creative Commons Attribution 4.0 International License. 


\section{Factors Affecting Participants' Perceptions on e-Satisfaction}

Qualitative data analysis was also carried out with the responses of 252 participants who answered the open-ended question on e-Satisfaction. The analysis of open-ended questions revealed divergence among the answers. The factors most linked to satisfaction are the advantages of e-Learning, whilst the factors leading to dissatisfaction are the obstacles faced during the e-Learning experience. For the advantages only three themes emerged; whereas for the obstacles there were 10 emerging themes. The themes and their corresponding frequencies and percentages are presented in Table 5 .

Table 5

Emerging Themes for e-Satisfaction

\begin{tabular}{|c|c|c|c|}
\hline & Themes & Freq. & Pct (\%) \\
\hline \multirow{10}{*}{$\begin{array}{l}\frac{\mathscr{d}}{0} \\
\frac{\pi}{\mathbb{W}} \\
\frac{0}{0}\end{array}$} & Technical problems & 127 & 50.4 \\
\hline & Evaluation problems & 46 & 18.3 \\
\hline & Announcement & 14 & 6.0 \\
\hline & $\begin{array}{l}\text { Scheduling problems about } \\
\text { teaching }\end{array}$ & 13 & 5.2 \\
\hline & Lack of instructional content & 11 & 4.4 \\
\hline & Lack of time & 9 & 4.0 \\
\hline & Intensive curriculum & 8 & 3.0 \\
\hline & Student affairs & 6 & 2.4 \\
\hline & Lack of mobile compatibility & 3 & 1.2 \\
\hline & Usability/ Interface & 2 & 0.8 \\
\hline \multirow{3}{*}{ 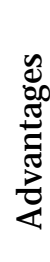 } & $\begin{array}{l}\text { Advantage of delivery } \\
\text { approach }\end{array}$ & 25 & 0.8 \\
\hline & Competencies of e-tutors & 5 & 2.0 \\
\hline & $\begin{array}{l}\text { Variety of instructional } \\
\text { materials }\end{array}$ & 1 & 0.4 \\
\hline
\end{tabular}

Bearing in mind that the themes consist of factors which affect participants' perceptions, it is not surprising at first sight to see more obstacles than advantages, with technical problems at the top. Participants stated that technical problems mostly influenced their dissatisfaction during online lessons, in particular, the experiencing of technical problems during asynchronous lessons due to virtual classroom software issues. One of the participants stated the following: 
"I couldn't watch the lesson videos because of my low speed internet connection. There is no high speed connection where I am living, so I have to connect through my GSM operator. So videos and virtual classroom software is a problem for me due to connection speed".

Another problem affecting satisfaction was the evaluation system. Especially, participants want online exams instead of face-to-face exams, more active usage of the announcement system by instructors, and the provision of guidance about time management from instructors.

Participants stated that they became bored of lessons, which decreased their interest, where they were presented by instructors with a monotone delivery. They also stated their satisfaction about usage of the system wherever and whenever they wanted, instructors being experts in their respective areas and the variety of materials. On the variety of material, one participant stated:

"Every person has a different working style. Some like working with a printed book, some of them via images or audio materials; so I am very pleased to have materials with different styles".

Participants pointed out some negative aspects which they came across during the e-learning process that affected their satisfaction. They especially stated technical problems that originated from both themselves and the system, and delays experienced within the evaluation period as issues that negatively affected their satisfaction. In addition to these, it was determined that content offered in different formats and the academic experience of the instructors positively affected them.

\section{Discussion and Conclusion}

The purpose of this study was to explore the participants' readiness and expectations before, and the satisfaction levels after, an online learning experience. In accordance with this purpose, answers given by participants to the open-ended questions, in addition to the quantitative data from the scales, were analyzed.

Prior to the online course, it was observed from results of the quantitative analysis that online learners put more emphasis on factors that affect success as being access to technology and ICT competencies which can be perceived as individual characteristics as a whole. In other words, it can be said that the participants' readiness can be interpreted in terms of these variables. Similarly, findings from the qualitative analysis also revealed factors affecting participants' perceptions about their e-Readiness as individual factors, namely accessibility, getting a degree,

This work is licensed under a Creative Commons Attribution 4.0 International License. 
delivery approach and time management. Hence, the findings from the two data sources were almost in parallel, as they both emphasize the importance of individuality and accessibility.

Hence, what participants expect especially from the distance education program is having an effective learning experience through interacting with the instructors and other participants. Results of the qualitative data show that they have an expectation of being able to fill the deficiency of not being able to attend within the formal education system because of their individual responsibilities. Based on this, it is observed that state of the access type, which supports the interaction, creates an expectation.

After the online learning experience, it was observed from the results of quantitative analysis that the participants' satisfaction levels were mainly affected by instructional content, communication and usability, and teaching process. The dimension they were most happy about was instructional content, which can be said to be the heart of online learning. On the other hand, qualitative data results reveal the participants' satisfaction levels were affected by the dimensions of advantage of delivery approach, competencies of e-tutors and variety of instructional materials. This finding supports the finding of the study of Ilgaz and Aşkar (2013), which showed the perceived benefit levels of students in a distance education program related to online courses are important in affecting their satisfaction levels. Cole, Shelley and Swartz (2014) also researched in a three year study, the factors affecting satisfaction regarding online education at a university. As a result, they determined that the online education is convenient as a positive factor, but that the rarity of interaction is a negative factor which affects satisfaction. The primary negative factors which affect satisfaction are related to technical problems. On the other hand, as it is a user-friendly system and it makes it possible to solve problems quickly, these are seen as the important factors affecting participant satisfaction levels (Lee, 2014). Time management, which is something that affects student satisfaction and originates from individual characteristics, also affects their satisfaction. Especially in an online learning environment, it is essential that participants should have improved pre arrangement abilities in order to be able to work without a locus of control (Zimmerman, 2002). The effects of the ability of the individual in arranging the learning environment and process on their academic success and satisfaction are proved by the research (Lynch \& Dembo, 2004; Barnard, Paton \& Lan, 2008).

As a summary, the variables presented in Figure- 3 came out of this research study as the major variables that affect e-readiness and e-satisfaction. 


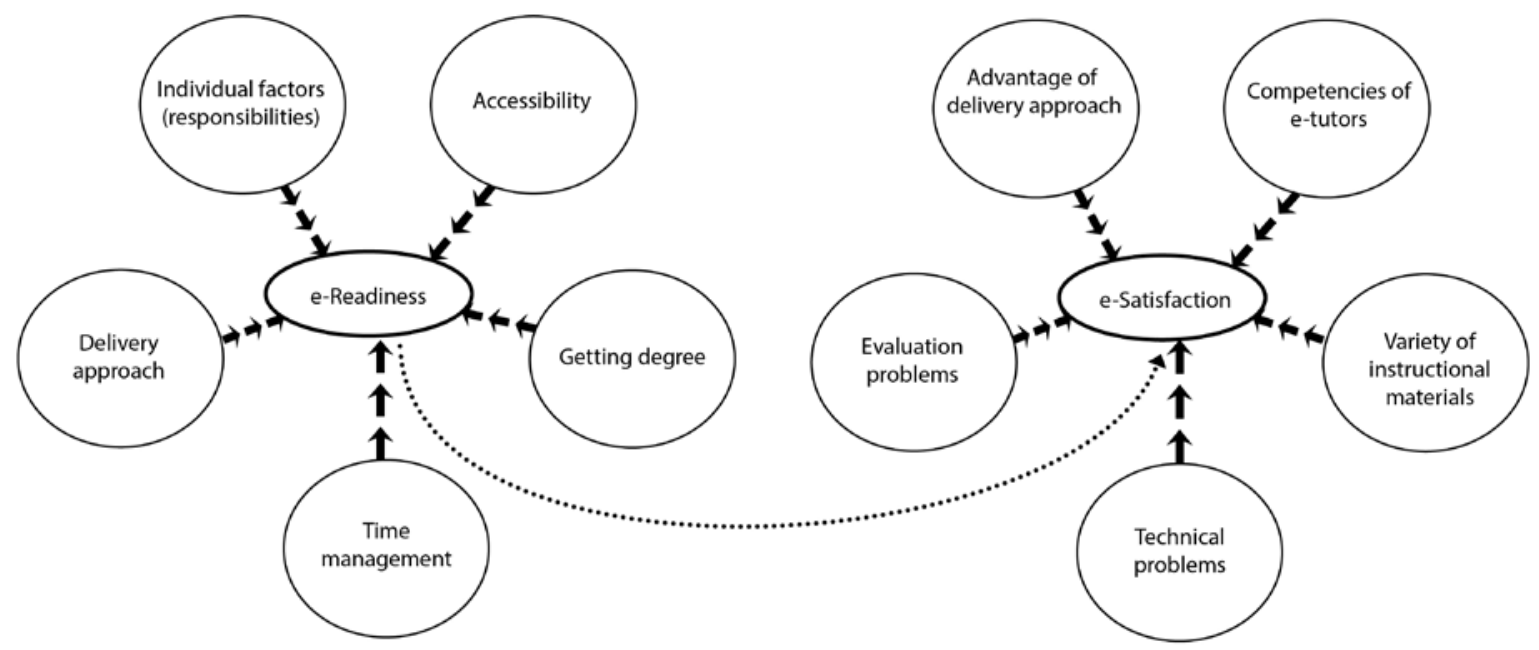

Figure 3. Major variables affecting readiness and satisfaction.

At the beginning of the e-Learning process, individuals should have known to what extent it meets their needs and also, they should have determined what properties it has. In terms of this, it has been shown that their expectations are more objective and this situation provides participants with an opportunity to take greater advantage of the system. It is essential to minimize factors that negatively affect satisfaction by evaluating them in order to highlight the system's successes which originated in negative situations in distance education. These negative situations drive students away from distance education, sometimes permanently. Recent studies on the relation between various variables prior to, or at the end of e-Learning, have shown that individuals' academic success scores, and the satisfaction levels, can be analyzed and the overall quality of e-Learning evaluated. 


\section{References}

Aoki, K. (2010). The Use of ICT and e-Learning in Higher Education in J apan. World Academy of Science, Engineering \& Technology, 66, 868-872.

Barnard, L., Paton, V., \& Lan, W. (2008). Online self-regulatory learning behaviors as a mediator in the relationship between online course perceptions with achievement. The International Review Of Research In Open And Distance Learning, 9(2). Retrieved from http:// www.irrodl.org/ index.php/irrodl/article/view/ 516/ 1035

Beqiri, M. S., Chase, N. M. \& Bishka, A. (2009). Online course delivery: An empirical investigation of factors affecting student satisfaction. J ournal of Education For Business, 85(2), 95100.

Cole, M., Shelley, D., \& Swartz, L. (2014). Online instruction, e-learning, and student satisfaction: A three year study. The International Review Of Research In Open And Distance Learning, 14(6). Retrieved from http:// www.irrodl.org/index.php/irrodl/article/view/1748/3179

Dada, D. (2006). E-Readiness for developing countries: Moving the focus from the environment to the users. The Electronic J ournal on Information Systems in Developing Countries, 27(6), 1-14.

Darab, B. \&Montazer, G. A. (2011). An eclectic model for assessing e-learning readiness in the Iranian universities. Computers \& Education, 56(3), 900-910.

Gulbahar, Y. \& Cinar, M. (2011). Success indicators in an e-learning environment in higher education. IADIS International e-Learning Conference, Rome, Italy.

Gülbahar, Y. (2012). Study of developing scales for assessment of the levels of readiness and satisfaction of participants in e-learning environments. Ankara University J ournal of Faculty of Educational Sciences, 45(2), 119-137. DOI: 10.1501/Egifak_0000001256. URL: http:// dergiler.ankara.edu.tr/ dergiler/ 40/1731/ 18388.pdf

Hanafizadeh, P., Hanafizadeh, M. R. \& Khodabakhshi, M. (2009). Taxonomy of e-readiness assessment measures. International J ournal of Information Management, 29(3), 189195.

Hung , M.,Chou, C., Chen, C. \& Own, Z. (2010). Learner readiness for online learning: Scale development and student perceptions, Computers \& Education, 55, 1080- 1090.

This work is licensed under a $\underline{\text { Creative Commons Attribution } 4.0 \text { International License. }}$ 
Ilgaz, H., \& Aşkar, P. (2013). The contribution of technology acceptance and community feeling to learner satisfaction in distance education. Procedia - Social and Behavioral Sciences, 106(0), 2671-2680. doi: http:// dx.doi.org/ 10.1016/j.sbspro.2013.12.308.

J ung-Wan, L. \& Mendlinger, S. (2011). Perceived self-efficacy and its effect on online learning acceptance and student satisfaction. J ournal of Service Science \&Management, 4(3), 243-252.

Keramati, A., Afshari-Mofrad, M. \& Kamrani, A. (2011). The role of readiness factors in e-learning outcomes: An empirical study. Computers \&Education, 57(3), 1919-1929.

Krippendorff, K. (2004). Content analysis: An introduction to its methodology (2nd ed.). Sage Publications.

Landis, J . R. \& Koch, G. G. (1977). The measurement of observer agreement for categorical data. Biometrics, 33(1), 159-174.

Lee, J . (2014). An exploratory study of effective online learning: Assessing satisfaction levels of graduate students of mathematics education associated with human and design factors of an online course. The International Review of Research In Open And Distance Learning, 15(1). Retrieved from http:/ / www.irrodl.org/index.php/irrodl/article/view/ 1638/ 2812, 23.09.2014.

Lee, H.-J ., \& Rha, I. (2009). Influence of structure and interaction on student achievement and satisfaction in web-based distance learning. Educational Technology \& Society, 12(4), 372-382.

Lynch, R. \& Dembo, M. (2004). The relationship between self-regulation and online learning in a blended learning context. International Review of Research in Open and Distance Learning. http:// www.irrodl.org/ content/v5.2/lynch-dembo.html

Machado, C. (2007). Developing an e-readiness model for higher education institutions: Results of a focus group study. British J ournal of Educational Technology, 38(1), 72-82.

Miles, M.B. \& Huberman, A.M. (1994). Qualitative data analysis. Thousand Oaks, CA: Sage.

Palmer, S. R. \& Holt, D. M. (2009). Examining student satisfaction with wholly online learning. J ournal of Computer Assisted Learning, 25(2), 101-113.

Palmer, S. \& Holt, D. (2010). Students' perceptions of the value of the elements of an online learning environment: Looking back in moving forward. Interactive Learning Environments, 18(2), 135-151.

This work is licensed under a $\underline{\text { Creative Commons Attribution } 4.0 \text { International License. }}$ 
Pena, M. \&Yeung, A. (2010). Satisfaction with online learning: does students' computer competence matter? International J ournal Of Technology, Knowledge \& Society, 6(5), 97-108.

Shraim, K. \& Khlaif, Z. (2010). Students' readiness towards e-learning. A case study of virtual classrooms for secondary education in Palestine. The 3rd Annual Forum on e-learning Excellence in the Middle East. Dubai. 1-4 Feb 2010.

Stephen, M., Mutula, S. M. \& Brakel, P. (2006). An evaluation of e-readiness assessment tools with respect to information access: Towards an integrated information rich tool. International J ournal of Information Management, 26, 212- 223.

Strauss, A., \& Corbin, J . (1990). Basics of qualitative research: Grounded theory procedures and techniques. Newbury Park, CA: Sage Publications, Inc.

Watkins, R., Leigh, D. \& Triner, D. (2004). Assessing readiness for e-learning. Performance Improvement Quarterly, 17(4), 66-79.

Yurdugül, H. \& Strakaya, D. A. (2013). The Scale of Online Learning Readiness: A study of validity and reliability. Education and Science, 38(169), 391-406.

Zimmerman, B. J . (2002). Becoming a self-regulated learner: An overview. Theory into Practice, 41(2), 64 - 70. doi: 10.1207/s15430421tip4102_2.

(C) Ilgaz and Gülbahar

\section{Athabasca University $\mathbf{Z}$}

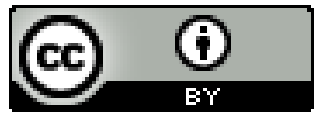

